Psychological Medicine, 1991, 21, 1-9

Printed in Great Britain

EDITORIAL

\title{
Chronic fatigue syndrome and depression: conceptual and methodological ambiguities ${ }^{1}$
}

We are simply not accustomed to the conceptual handling of complex entities where many factors, all vital, maintain a balance.

(Cunningham, 1981, p. 609.)

Psychological and somatic factors contribute and interact across the spectrum of health and illness. Their relative influence varies from disorder to disorder and from case to case, and specific instances of disorder might in theory be plotted along a continuum to represent different weightings of psychological and somatic causation (Lipowski, 1986; Oken, 1987). We can criticize such a model for its implied dualism, and it is misleading to conceive of the psychological and somatic as distinct and mutually exclusive categories. Nevertheless, as levels of explanation, one may be more appropriate than the other, and it is thus legitimate to ask whether a given disorder should be understood primarily in somatic terms or whether a psychological model is more likely to advance our understanding.

A disorder whose aetiology has been the subject of recent controversy is chronic fatigue syndrome (CFS), also commonly known as postviral fatigue syndrome and myalgic encephalomyelitis. The issue of terminology is in itself controversial, and there may prove to be differences between these syndromes (Ramsay, 1988). Nevertheless, CFS will be the general term employed here; it is arguably the most appropriate at this stage of our understanding since it makes no assumptions about aetiology (Holmes et al. 1988; Lloyd et al. 1988). The central feature of the disorder is persistent and excessive fatiguability, and this may be accompanied by various other somatic and psychological symptoms, including acheing muscles and joints, headache, sore throat, painful lymph nodes, muscle weakness, sleep disturbance, mental fatigue, difficulty in concentrating, emotional lability and depression (David et al. 1988 a; Holmes et al. 1988). Its nature and causes are as yet undetermined, and the research to date suggests that it is an intriguingly complex disorder, with both biological and psychological features. On the one hand, there is accumulating evidence of biological abnormalities suggestive of viral infection and immunological dysfunction (see Archer, 1987; Bannister, 1988; David et al. 1988 b; Straus, 1988). However, there are inconsistencies between studies in the results obtained, no single defining factor has emerged, and the clinical significance of the abnormalities found has been questioned (Hellinger et al. 1988; Jacobson, 1988; Straus, 1988; Straus et al. 1988; Swartz, 1988). A detailed description of this body of research is beyond the scope of this paper. On the other hand, there is evidence of psychiatric disorder in a significant number of patients, with depression predominating. These findings might be taken to offer some indirect support for the hypothesis that CFS and depression are similar syndromes, with common aetiological factors. However, cross-sectional data are notoriously difficult to interpret, and there are various ways in which depression and psychological vulnerability in general could be implicated in CFS. Though depression will be the focus of this discussion, many of the arguments presented are relevant to other psychological categories, such as anxiety or somatization disorder; these have also been linked with CFS but to a lesser extent than depression.

\section{CHRONIC FATIGUE AND DEPRESSION: THE EVIDENCE}

One early study (Morrison, 1980), examined the records of patients with an isolated diagnosis of

1 Address for correspondence: Dr Colette Ray, Department of Human Sciences, Brunel University, Uxbridge, Middlesex, UB8 3PH. 
fatigue. It was concluded that the diagnosis was associated with physical problems, most commonly an earlier virus, in 69 patients, and with psychological problems, most commonly depression, in 72 patients. For 21 patients there were indications of both physical and psychological problems. Psychological problems were more likely to be identified in those patients whose fatigue had lasted for a period of more than four months. Other studies have employed more rigorous forms of assessment, comprising either standardized clinical interviews or rating scales. Taerk and colleagues (1987) found a high prevalence of DSM-III affective disorder in patients suffering from postinfectious fatigue, and 16 of the sample of 24 had scores of 9 or more on the Beck Depression Inventory. Similarly, more than half of another sample of patients who identified fatigue as a main problem had scores higher than 10 on this self-report measure (Kroenke et al. 1988). The Millon Behavioral Health Inventory was also employed in the latter study; patients with fatigue had higher scores than controls on all six psychogenic attitude scales, with the greatest differences occurring for pre-morbid pessimism and somatic anxiety. Manu and colleagues (1988) found that $67 \%$ of a sample of 135 patients attending a fatigue clinic had one or more psychiatric disorders, based on DSM-III, with depression being the most common diagnosis; the research workers concluded that depression was a major cause of fatigue, and that CFS is an inappropriate diagnosis in cases which meet the criteria for a psychiatric disorder. Another study to employ a standardized clinical interview is that of Wessely \& Powell (1989); using the Research Diagnostic Criteria, but excluding fatigue as a symptom, $47 \%$ of CFS patients attracted a diagnosis of major depression. Other measures used in this study were the General Health Questionnaire and the Hospital Anxiety and Depression Scale; on all indices, the CFS group had higher levels of psychological disturbance than a control group of patients with neuromuscular disorders, though lower levels than a second control group of patients with a primary diagnosis of major depression.

Might depression then play a causal role in CFS? The strongest form of this hypothesis would be that, at least for a significant number of patients, CFS is no more than depression masquerading as a physical illness. This would seem at first sight to have the attraction of parsimony. Depression is a well-established diagnostic category, with recognized criteria for assessment and pathways for treatment, and it can provide a plausible account of the fatigue and other somatic symptoms reported by patients with CFS. These are common concomitants of depression (Beck, 1967), and they may be an early indication of the disorder and parallel its course, diminishing in severity during treatment (Wittenborn \& Buhler, 1979; Cadoret et al. 1980). Beck (1967) noted fatigue as a characteristic in $78 \%$ of a sample of severely depressed patients, compared with $40 \%$ of controls, and fatigue in the general population is correlated with both depression and anxiety (Montgomery, 1983; Chen, 1986). Furthermore, there is little evidence as yet to suggest that fatigue is more of a problem in CFS than in depression; Wessely \& Powell (1989) found no significant differences between their CFS group and affective controls on measures of either physical or mental fatigue.

The fact that patients may present with somatic symptoms as their chief complaint, and attribute these to a somatic disorder, does not necessarily undermine a diagnosis of depression. Within the spectrum of a depressive disorder, patients who experience physical distress as part of the syndrome have differing views of its nature and source. Some patients adhere to a somatic model of their illness, some feel that it is primarily psychological, while others perceive both somatic and affective dimensions to their condition with no clear view as to which is primary (Katon et al. 1982). However, there are conceptual and methodological ambiguities in relating CFS to depression which make it difficult to interpret the evidence. While there may be an association between the two syndromes, this in itself cannot justify an assertion that one has aetiological primacy. To the extent that the association reflects a causal relationship, this might indicate either the influence of depression on the development of CFS or the capacity of CFS to produce symptoms of depression. Alternatively, the association might be due to some other factor with which both syndromes are linked; such a factor might be implicated in the aetiology of both CFS and depression, so that there is a tendency for these to co-occur. Nor, having identified commonalities between the syndromes of CFS and depression, can one proceed to identify one with the other, since one set of symptoms may result from a variety of causes. 


\section{INTERPRETING DEPRESSION IN MEDICAL ILLNESS}

It may be tempting to assign a causal role to psychological variables in the absence of an established organic explanation for CFS, but it is worth remembering that, historically, many disorders have at one time or another been conceived of in psychological terms, with this model being abandoned when a somatic cause has been identified (Angell, 1985). It is interesting, in the context of the present discussion, that the pendulum has recently swung back in the other direction, with a refocusing of attention on psychological and social factors which enhance vulnerability to disease; however, these factors are seen as neither necessary nor sufficient pre-requisites (Engel, 1962), and few would wish to argue that conditions such as cancer or tuberculosis should be regarded as psychological disorders. It is possible to adhere to a somatic model of CFS, though with the nature of this as yet unspecified, and to interpret the psychological evidence in ways compatible with this.

First, several kinds of medical illness elicit symptoms which are also symptoms of psychological disorder, where these are a direct result of the underlying physical condition. In neurological disorders, such as Parkinson's disease and multiple sclerosis, patients may present with symptoms of a depressive syndrome; the same applies to some endocrine, metabolic and nutritional disorders, and even to some neoplastic diseases (Derogatis \& Wise, 1989). To take thyroid disorder as an illustration, a proportion of newly diagnosed hyperthyroid patients meet the formal criteria for a depressive or anxiety disorder, but these psychiatric symptoms are resolved with effective management of the thyrotoxicosis (Kathol \& Delahunt, 1986; Kathol et al. 1986). Depression is a feature also of early hypothyroidism; overlapping symptoms include fatigue, depressed mood, weight gain, sleep problems, difficulties in concentrating, loss of libido, constipation and anhedonia; the symptoms they have in common are more numerous than those specific to either disorder (Derogatis \& Wise, 1989). Changes in mood are also commonly associated with infection, as are fatigue and malaise. Mood changes can occur before other symptoms such as fever, and last into the convalescent period (Canter, 1972). Infectious mononucleosis can have persistent consequences in some patients (Hendler \& Leahy, 1978; Hendler, 1987). One study found that women, but not men, who had had infectious mononucleosis one year previously had higher scores than a normative sample on anxiety, somatic symptoms and depression (Cadie et al. 1976), and this might reflect a persisting effect of the virus. Thus, the presence of psychological symptoms does not in itself indicate that a disorder has a psychological basis, though the existence of depressive symptoms implies that the disorder may involve processes which are in some way linked to depression. One hypothesis is that the depression associated with viral and post-viral states is due to a virally induced neurochemical change (Sachar, 1975).

A second way in which physical illness can cause depression is as a reaction to the fact of the illness and its effects. Depression and anxiety are common in patients with cancer (Derogatis et al. 1983; Maguire, 1984), stroke (Newman, 1984) and heart disease (Langosch, 1984), and disturbance may reach psychiatric proportions in a significant number. Loss of function and general malaise, as well as threat to life, will have adverse psychological consequences, and it has been suggested that the depression and low self esteem which accompanies prolonged or debilitating illness might be more appropriately construed as demoralization (Derogatis \& Wise, 1989) or despondency (Cassem, 1987) rather than as a psychiatric disorder. Physical illness is particularly likely to give rise to affective disorder if it is chronic, and it is worth noting that patients in CFS samples have often been ill for a considerable time. Most will severely restrict their activity, because of fatigue, and this will result in a loss of social and other rewards, and sow the seeds of disengagement and depression. The lack of physical exercise in itself could have a direct effect upon mood, and there is mounting evidence of a relationship between physical activity, emotional stability and depression (Lobstein et al. 1989). An additional factor which may foster depression in patients with CFS is the ambiguity of the illness. Ambiguity is a key determinant of how effectively people will cope with a stressor (Shalit, 1977); it is a difficulty cited by cancer patients, some of whom feel that neither they nor their physicians have a clear understanding of aetiology or of the factors which determine outcome (Ray \& Baum, 1985). Arguably, this kind of uncertainty is even greater in the case of 
CFS, and these patients may in addition have difficulty in obtaining recognition of the fact that they are ill (Gadd, 1989).

\section{ASSESSING DEPRESSION IN MEDICAL ILLNESS}

The criteria for a diagnosis of depression in systems such as DSM-III-R (American Psychiatric Association, 1987) and the Research Diagnostic Criteria (Spitzer et al. 1978) include features which can be a manifestation of physical illness, such as changes in sleep, appetite, energy, motor activity and concentration. Rating scales such as the Beck Depression Inventory (Beck, 1978) similarly incorporate items which are not specific to depression. Such symptoms are legitimate criteria for the assessment of depression in the absence of physical illness, but their status is ambivalent when the possibility of this has not been excluded (Endicott, 1984; Popkin, 1987; Snaith, 1987). Kathol \& Delahunt (1986), in the study of hyperthyroid patients referred to earlier, found that the number of patients classified as depressed was considerably reduced when somatic factors were deemphasized, and they advocated stricter criteria for the assessment of depression in medical contexts. A key problem in the case of an ambiguous disorder such as CFS is that the appropriateness of standard measures of depression will depend upon the assumed nature of the illness, while our concept of the latter may be shaped by the results obtained from such measures. If we assume that organic factors are insignificant and use standard criteria, then there is a risk of false positives. If, on the other hand, we assume that the illness has a somatic basis, and employ stricter criteria in assessing depression, then there is a corresponding risk of false negatives. In a recent study, which employed a variety of measures, CFS patients showed elevated scores particularly on those affective scales which included somatic items as a large component (Millon et al. 1989). Future studies should employ measures appropriate to the context of medical illness, at least in parallel with other measures, in order to allow for such distinctions to be made.

If diagnostic criteria are used, careful consideration should be given to the symptoms which are included. Wessely \& Powell (1989), in their application of the Research Diagnostic Criteria, took a step in the direction of controlling for physical illness by excluding fatigue as a criterion. Another study excluded physical symptoms which typically characterise CFS (Kruesi et al. 1989); however, they still obtained a high rate of psychiatric diagnoses and, somewhat surprisingly, this was not significantly changed by rescoring the excluded symptoms as psychiatrically relevant. Similar considerations apply in the selection and application of self-report measures. The Hospital Anxiety and Depression Scale (Zigmund \& Snaith, 1983) was devised for use with physically ill patients. Items for depression are based on the anhedonic state, though they include one item the response to which could reflect difficulties in concentration. The scale was used by Wessely \& Powell (1989); in the data as presented, the scores for anxiety and depression have been summed which makes them difficult to interpret, but the pattern of results obtained was similar to that obtained using other measures, with the CFS group having lower scores than the affective group but higher scores than those of the neuromuscular controls. Another potentially useful instrument is the Profile of Mood States (McNair et al. 1971); this yields separate assessments for depression, fatigue, vigour, confusion, tension and anger and was employed by Millon and colleagues in their study of CFS (1989). Finally, the SCL-90 (Derogatis et al. 1976; Derogatis, 1977) provides a comprehensive measure of psychological distress, and it is available also in short form (Derogatis \& Melisaratos, 1983). It includes a subscale for depression, together with factorially distinct subscales comprising somatic and cognitive items respectively.

If the Beck Depression Inventory is used in the context of medical illness, it may be advisable to score cognitive-affective and somatic items separately, the latter being represented by the last 7 items on the scale. A study which adopted this procedure (Cavanaugh et al. 1983) found that medically ill patients had lower scores than a psychiatrically depressed group on the cognitive-affective subscale, while the somatic subscale failed to distinguish between the two groups. Indeed, these research workers noted that most vegetative symptoms on the Beck Depression Inventory did not 
discriminate well for overall severity of depression in either group. The symptoms which discriminated most effectively were suicidal ideation, sense of failure, sense of punishment, loss of social interest, indecision and dissatisfaction (Clark et al. 1983); these criteria may thus provide an appropriate index of severity of depression in the context of both medical and psychiatric illness.

Measures which screen out somatic symptoms take into account the fact that these symptoms are commonly associated with physical illness in the absence of depression. However, as argued in the preceding section, some physical illnesses may directly produce cognitive and affective symptoms characteristic of depression, and patients may also become depressed as a reaction to the illness and the difficulties that this imposes. A patient can thus fulfil the criteria for depression across the range without this indicating an independent psychological vulnerability. Endicott (1984) has suggested that the term 'depressive syndrome' is preferable to 'depressive disorder' in such circumstances, since the former makes no implications about aetiology. Problems of causality will not necessarily be resolved by refinements in assessment procedures, though discriminating between symptom criteria will help to determine to what extent it is legitimate to talk of a depressive syndrome in the context of CFS. An indication that depression preceded the onset of a physical illness would, however, suggest that it plays some causal role and there is indeed some evidence of psychiatric disorder antedating the onset of chronic fatigue (Taerk et al. 1987; Kruesi et al. 1989; Wessely \& Powell, 1989). Nevertheless, such evidence too needs to be carefully scrutinized. Affective disorder, including somatic complaints, might be a prodromal feature, and subjective reports of one's past state may be contaminated by current experiences.

\section{HETEROGENEITY, CFS AND DEPRESSION}

While there may be overlaps between the two syndromes, there are also some divergences which should not be overlooked. First, in no study is it the case that all patients with chronic fatigue have fitted a psychiatric diagnostic category or have had high scores on scales of psychological disorder. It should also be noted that the samples in several of the studies cited were selected for long-standing illness, and emotional problems may be less common in the context of primary care and shorterterm illness (Wessely, 1989). Secondly, while both CFS and depressed patients report somatic symptoms other than fatigue, the former do so to a greater extent, and a higher percentage report fatigue precipitated by exercise (Wessely \& Powell, 1989). Thirdly, depression is a multifaceted phenomenon, with cognitive, motivational, emotional and somatic dimensions (Beck, 1967). Do CFS patients show the lower self esteem and high levels of self criticism common in depression? Do they show a characteristic lack of initiative and effort or, in contrast, high levels of motivation but without the capacity to achieve their goals? Diagnostic categories and rating scales collapse these multiple dimensions and provide a single, umbrella descriptor or score. A finer description of the phenomenology of depression, as well as of fatigue (David $e t$ al. 1988b), is called for in charting overlaps and divergences between CFS and depression. It is, unfortunately, rare for depression to be assessed multidimensionally in research settings.

A major limitation in considering the relationship between CFS and depression is that neither is a clear-cut syndrome. The structure of depression is largely unresolved (Kendell, 1976). There are no unique symptoms and few symptoms common to all cases, and this heterogeneity in presentation is paralleled by heterogeneity in aetiology and response to treatment (Blumenthal, 1971). The ambiguous nature of depression cuts both ways in this discussion. On the one hand, it could be argued that a label of depression can at most provide an incomplete explanation of CFS; it tells us neither why the disorder has occurred nor why it should manifest in this particular form. Conversely, it could be argued that CFS can readily be regarded as a variant of the syndrome given the latter's breadth and variability! Similarly, with regard to CFS, we are dealing with a condition which is heterogeneous with respect to symptoms and possibly aetiology too. Patients may present with a primary complaint of fatigue, but the range of other somatic and psychological symptoms reported varies from individual to individual. Research is needed to determine whether there are any 
regularities in the patterns of symptoms presented; any such patterns might or might not be associated with different causal antecedents.

We should be cautious of implicitly reifying either CFS or depression, when these diagnostic categories are little more than summary descriptors of symptoms. This is not to argue that CFS should be researched without reference to the field of psychological disorder; an analysis of commonalities might illuminate processes which are germane to both.

\section{A WORKING MODEL}

It is difficult to disentangle the causal relationships linking CFS and depression. Such complexities are not limited to the domain of psychological observations. There would be similar difficulties, for example, in interpreting evidence of a persisting virus in CFS. This could be taken to indicate that the virus plays a direct and ongoing role in the illness; alternatively, it could suggest cellular immune impairment caused by something other than the virus, or an immunoregulatory disorder which has been induced or augmented by the virus (Straus et al. 1985). It is probable that CFS is not a disorder with a single specific cause, but the outcome of interacting processes at biological and psychological levels. Many diseases are aetiologically complex, and CFS would not be unique in this respect: 'Causation in both infectious and non-infectious disease involves a complex interplay of agents, environmental and host factors.... Different qualitative and quantitative mixes of the agent, environment and host may result in the same clinical and pathological diseases under different circumstances' (Evans, 1978, p. 254). To the extent that depression plays a causal role, it may do so in interaction with other factors, constituting part of but not the whole explanation of chronic fatigue. There might be an initiating acute infection, with associated symptoms of lassitude, fatiguability and weakness; these normally transient symptoms could then be perpetuated in the psychologically vulnerable in the absence of active viral involvement (Imboden et al. 1959; Imboden et al. 1961). Avoidance behaviour, which was originally adaptive, could result in decreased tolerance of exertion, so that symptoms occur at progressively lower levels of exertion and produce a selfsustaining cycle of inactivity, fatigue and depression (Wessely et al. 1989). Alternatively, there might be an ongoing biological disorder, but with psychological factors promoting this and playing a part in its maintenance.

If a virus is causally implicated in CFS, then it may be more difficult to combat this in the context of depression. Several studies of patients with depressive disorder have demonstrated altered cellmediated immunity (Schleifer et al. 1984; Kronfol et al. 1987; Murphy et al. 1987), though others have failed to confirm this (e.g. Albrecht et al. 1985). In a recent and relatively extensive study, Schleifer and colleagues (1989) compared depressed patients with matched controls, and found no overall differences between the two groups in mitogen-induced lymphocyte proliferation, lymphocyte subsets or natural killer cell activity. However, there were differences related to age and to the severity of depression, suggesting that altered immunity is not a general characteristic of depression but that it does occur in subgroups of patients. Furthermore, the clinical significance of such immunological findings has been questioned (Hall, 1985; Hall, 1987; King \& Cooper, 1989). The implications of a relationship between depression and altered immunity are thus unclear, but it is possible that in some cases depression may foster an aberrant immune response to viral infection (Miller et al. 1986).

A second way in which psychological factors might influence somatic dysfunction would be through a cyclical interaction between biochemical mechanisms and psychological status. A dysregulation of the former might be produced by a non-psychological agent, but then be sustained or amplified by psychological processes which feedback into the same mechanisms. One candidate for such a common path is the hypothalamic-pituitary-adrenal axis. This system is involved in the regulation of immune system functioning through the suppressive effects of corticosteroids (Antoni, 1987; Cox, 1984), and the hypothalamus regulates many of the functions which characterize the somatic features of both CFS and depression. A heightened secretion of cortisol is seen in depression (Sachar, 1980). Charlton \& Ferrier (1989) have reviewed the range of abnormalities 
associated with the axis that have been observed in this context, and suggest that these may reflect an increased secretion of corticotropin-releasing hormone and a neurally mediated hyperresponsivity to ACTH. A significant proportion of patients with major depressive disorder show a resistance to cortisol suppression using dexamethasone (Carroll, 1982); Taerk and colleagues (1987) employed this test in their study of fatigue patients, but found that the majority showed a normal response. The test, however, may be less sensitive in such patients than in severely depressed inpatients, and it has been suggested that major changes in the production of cortisol are associated with the more severe symptoms of depression, psychotic symptoms in particular (Christie et al. 1986). It is possible that CFS and depression both involve neuroendocrine disturbance but with a different pattern in each case. Demitrack and colleagues (1989) compared CFS patients with healthy controls, and found lower basal cortisol levels and higher basal ACTH in the former. Patients with affective disorder, in contrast, tend to show basal hypercortisolism and normal levels of ACTH.

At this stage it would obviously be unwise to discount the influence of either organic or psychological factors in CFS, and it becomes logically difficult to do so when one considers the interdependence between psychological, hormonal and immunological levels. A general working model of CFS should thus be comprehensive in its scope, to avoid a premature focus on any one set of causal variables. It should recognise that:

(a) the syndrome may be a non-specific response, with multiple somatic and psychological causes (Straus, 1988; Swartz, 1988);

(b) the relationship between these causes, somatic and psychological, may be interactive rather than additive (Archer, 1987; Taerk et al. 1987; David et al. 1988 b); the impact of any single factor would then depend upon the presence or absence of other coexisting conditions;

(c) the variables involved may have a reciprocal influence, leading potentially to a vicious circle and a cumulative decline in functioning;

(d) CFS may prove to be a heterogeneous condition, with different combinations of factors producing symptoms in individual cases.

If CFS is indeed aetiologically complex, it may be difficult to establish reliably the influence of any one factor. We should thus be wary of discarding hypotheses on the basis of inconsistent findings, and be alert to anomalies in the data which may be masked when these are considered in the aggregate.

COLETTE RAY

\section{REFERENCES}

Albrechı, J., Helderman, J. H., Schlesser, M. A. \& Rush, J. (1985). A controlled study of cellular immune function in affective disorders before and during somatic therapy. Psychiatry Research 15 , 185193.

American Psychiatric Association (1987). Diagnostic and Statistical Mamual of Mental Disorders 3rd edn, revised. American Psychiatric Association: Washington, DC.

Angell. M. (1985). Disease as a reflection of the psyche. New England Joturnal of Meticine 312. 15701572.

Antoni, M. H. (1987). Neuroendocrine influences in psychoimmunology and neoplasia: a review. Psychology and Health 1, 324.

Archer, M. I. (1987). The post-viral syndrome: a review. Journal of the Roval College of General Practitioners 37, 212-214.

Bannister, B. A. (1988). Post-infectious disease syndrome. Postgraduate Medical Journal 64, 559-567.

Beck, A. T. (1967). Depression: Clinical, Experimemal and Theoretical Aspects. Harper and Row: New York.

Beck, A. T. (1978). Depression Imventory. Center for Cognitive Therapy: Philadelphia.

Blumenthal, M. D. (1971). Heterogeneity and research on depressive disorders. Archives of General Psychiatry 24, 524-531.

Cadie, M., Nye, F. J. \& Storey, P. (1976). Anxiety and depression after infectious mononucleosis. British Journal of Psychiatry 128, $559-564$.

Cadoret, R. J., Widmer, R. B. \& Troughton, E. P. (1980). Somatic complaints: harbinger of depression in primary care. Journal of Affective Disorders 2, 61.70.

Canter, A. (1972). Changes in mood during incubation of acute febrile disease and effects of pre-exposure psychologic status. Psychosomatic Medicine 34, 424430.

Carroll, B. J. (1982). The dexamethasone suppression test for melancholia. British Journal of Psychiarry 140, 292304.

Cassem, N. H. (1987). Depression. In Massachusetts General Hospital Handbook of General Hospital Psychiatry (ed. T. P. Hackett and N. H. Cassem), pp. 227-260. PSG: Litleton, MA.

Cavanaugh, S., Clark, D. \& Gibbons, R. (1983). Diagnosing depression in the hospitalised medically ill using the Beck Depression Inventory. Psychosomatics 24, 809815.

Charlton, B. G. \& Ferrier, I. N. (1989). Hypothalamo pituitary adrenal axis abnormalities in depression: a review and a model. Psychological Medicine 19, 331-336.

Chen, M. K. (1986). The epidemiology of self perceived fatigue among adults. Preventive Medicine 15, 7481 .

Christie, J. E., Whalley, L. J., Dick, H., Blackwood, D. H. R., Blackburn, I. M. \& Fink, G. (1986). Raised plasma cortisol concentrations a feature of drug-free psychotics and not specific to depression. British Journal of Psychiary 148, 58-67. 
Clark, D. C., Cavanaugh, S. \& Gibbons, R. D. (1983). The core symptoms of depression in medical and psychiatric patients. Journal of Nervous and Mental Disease 171, 705-713.

Cox, T. (1984). Stress: a psychophysiological approach to cancer. In Psychosocial Stress and Cancer (ed. C. L. Cooper), pp. 149-169. Wiley: Chichester.

Cunningham, A. J. (1981). Mind, body and immune response. In Psychoneuroimmunology (ed. R. Ader), pp. 609-617. Academic Press: New York.

David, A., Wessely, S. \& Pelosi, A. (1988a). Myalgic encephalomyelitis, or what? Lancet ii, 100-101.

David, A. S., Wessely, S. \& Pelosi, A. J. (1988b). Postviral fatigue syndrome: time for a new approach. British Medical Journal 296, 696-699.

Demitrack, M. A., Dale, J. K., Gold, P. W., Chrousos, G. P. \& Straus, S. E. (1989). Neuroendocrine abnormalities in patients with chronic fatigue syndrome. Clinical Research 37, 532A

Derogatis, L. R. (1977). The SCL-90 Manual I: Scoring, Administration and Procedures for the SCL-90. Clinical Psychometric Research: Baltimore

Derogatis, L. R. \& Melisaratos, N. (1983). The Brief Symptom Inventory. Psychological Medicine 13, 595-605.

Derogatis, L. R. \& Wise, T. N. (1989). Anxiety and Depressive Disorders in the Medical Patient. American Psychiatric Press: Washington, DC.

Derogatis, L. R., Rickels, K. \& Rock, A. F. (1976). The SCL-90 and the MMPI: A step in the validation of a new self report scale. British Journal of Psychiatry 128, 280-289.

Derogatis, L. R., Morrow, G. R., Fetting, J., Penman, D., Piasetsky, S., Schmale, A. M., Henricks, M. \& Counicke, C. L. (1983). The prevalence of psychiatric disorders among cancer patients. Journal of the American Medical Association 249, 751-757.

Endicott, J. (1984). Measurement of depression in patients with cancer. Cancer 53, 2243-2248.

Engel, G. L. (1962). Psychological Development in Health and Disease. W. S. Saunders: Philadelphia.

Evans, A. S. (1978). Causation and disease: a chronological journal American Journal of Epidemiology 108, 249-258.

Gadd, R. (1989). Can psychologists help ME? The Psychologist 2, 17-19.

Hall, J. G. (1985). Emotion and immunity. Lancet ii, 325-327.

Hall, J. G. (1987). Depression, stress and immunity. Lancet ii, 221.

Hellinger, W., Smith, T., Van Scoy, R., Spitzer, P., Forgacs, P. \& Edson, R. (1988). Chronic fatigue syndrome and the diagnostic utility of Epstein-Barr virus early antigen. Journal of the American Medical Association 260, 971-973.

Hendler, N. (1987). Infectious mononucleosis and psychiatric disorders. In Viruses, Immunity and Mental Disorders (ed. E. Kurstak, Z. J. Lipowski and P. V. Morozov), pp. 81-94. Plenum: New York.

Hendler, N. \& Leahy, W. (1978). Psychiatric and neurologic sequelae of infectious mononucleosis. American Journal of Psychiatry 135, 842-844.

Holmes, G. P., Kaplan, J. E., Gantz, N. M., Komaroff, A. L., Schonberger, L. B., Straus, S. E., Jones, J. F., Dubois, R. E., Cunningham-Rundles, C., Pahwa, J., Tosato, G., Zegans, L. S., Purtilo, D. T., Brown, N., Schooley, R. T. \& Brus, I. (1988). Chronic fatigue syndrome: a working case definition. Annals of Internal Medicine 108, 387-389.

Imboden, J. B., Canter, A. \& Cluff, L. E. (1961). Convalescence from influenza: a study of the psychological and clinical determinants. Archives of Internal Medicine 108, 115-121.

Imboden, J. B., Canter, A., Cluff, L. E. \& Trever, R. W. (1959). Brucellosis III. Psychologic aspects of delayed convalescence. Archives of Internal Medicine 103, 406-414.

Jacobson, E. J. (1988). Chronic mononucleosis - it almost never happens. Postgraduate Medicine 83, 53-65.

Kathol, R. G. \& Delahunt, J. W. (1986). The relationship of anxiety and depression to symptoms of hyperthyroidism using operational criteria. General Hospital Psychiatry 8, 23-28.

Kathol, R. G., Turner, R. \& Delahunt, J. W. (1986). Depression and anxiety associated with hyperthyroidism: response to antithyroid therapy. Psychosomatics 27, 501-505.

Katon, W., Kleinman, A. \& Rosen, G. (1982). Depression and somatization : a review. American Journal of Medicine 72, 127 . 135 .

Kendell, R. E. (1976). The classification of depression: a review of the contemporary confusion. British Journal of Psychiary 129, 15-28.

King, D. J. \& Cooper, S. J. (1989). Viruses, immunity and mental disorder. British Journal of Psychiatry 154, 17.

Kroenke, K., Wood, D. R., Mangelsdorff, A. D., Meier, N. J. \& Powell, J. B. (1988). Chronic fatigue in primary care. Journal of the American Medical Association 260, 929934.

Kronfol, Z., Quinn, J., House, J. D. \& Nasrallah, H. A. (1987). Immunologic abnormalities in depressive illness. In Viruses, Immunity and Mental Disorders (ed. E. Kurstak, Z. J. Liposwki and P. V. Morosov), pp. 363-372. Plenum : New York.

Kruesi, M. J. P., Dale, J. \& Straus, S. E. (1989). Psychiatric diagnoses in patients who have chronic fatigue syndrome. Journal of Clinical Psychiary 50, 53-56.

Langosch, W. (1984). Behavioural interventions in cardiac rehabilitation. In Heallh Care and Human Behaviour (ed. A. Steptoe and A. Mathews), pp. 301-324. Academic Press: London.

Lipowski, Z. J. (1986). What does the word 'psychosomatic' really mean? A historical and semantic inquiry. In The Psychosomatic Approach: Contemporary Practice of Whole-person Care (ed. M. J. Christie and P. G. Mellet1), pp. 17-38. Wiley: London.

Lloyd, A., Wakefield, D., Boughton, C. \& Dwyer, J. (1988). What is myalgic encephalomyelitis? Lancet i, 1286-1287.

Lobstein, D. D., Rasmussen, C. L., Dunphy, D. E. \& Dunphy, M. J. (1989). Beta-endorphin and components of depression as powerful discriminators between joggers and sedentary middle-aged men. Journal of Psychosomatic Research 33, 293-305.

McNair, D. M., Lorr, M. \& Droppleman, L. F. (1971). Profile of Mood States. Educational and Industrial Testing Service: San Diego.

Maguire, P. (1984). The recognition and treatment of affective disorder in cancer patients. International Review of Applied Psychology 33, 479-491.

Manu, P., Lane, T., \& Matthews, D. (1988). The frequency of chronic fatigue syndrome in patients with symptoms of persistent fatigue. Annals of Internal Medicine 109, 554-556.

Miller, A. H., Silberstein, C., Asnis, G. M., Munk, G., Rubinson, E., Spigland, I. \& Norin, A. (1986). Epstein-Barr virus infection and depression. Journal of Clinical Psychiatry 47, 529.

Millon, C., Salvato, F., Blaney, N., Morgan, R., Mantero-Atienza, E., Klimas, N. \& Fletcher, M. A. (1989). A psychological assessment of chronic fatigue syndrome/chronic Epstein-Barr virus patients. Psychology and Health 3, 131-141.

Montgomery, G. (1983). Uncommon tiredness among undergraduates. Journal of Consulting and Clinical Psychology 51, $517-525$.

Morrison, J. D. (1980). Fatigue as a persisting complaint in family practice. Journal of Family Practice 10, 795-801.

Murphy, D., Gardner, R., Greden, G. F. \& Carroll, B. (1987). Lymphocyte numbers in endogenous depression. Psychological Medicine 17, 381-385.

Newman, S. (1984). The social and emotional consequences of head injury. International Review of Applied Psychology' 33, 427 455.

Oken, D. (1987). Coping and psychosomatic illness. In Handbook of Psychology and Health. Vol. 5. Stress (ed. A. Baum and J. E. Singer), pp. 109-135. Lawrence Erlbaum: Hillsdale, New Jersey.

Popkin, M. K., Callies, A. L. \& Colon, E. A. (1987). A framework for the study of medical depression. Psychosomatics 28, 27-33.

Ramsay, A. M. (1988). Myalgic Encephalomyelitis and Postviral Fatigue States: The Saga of Royal Free Disease. Gower Medical Publications: London.

Ray, C. \& Baum, M. (1985). Psychological Aspects of Early Breast Cancer. Springer Verlag: New York.

Sachar, E. J. (1975). Evaluating depression in the medical patient. In The Psychological Care of the Medically Ill: A Primer in Liaison 
Psychiutry (ed. J. J. Strain and S. Grossman), pp. 64-75. Appleton Century Crofts: New York.

Sachar, E. J. (1980). Hormonal changes in stress and mental illness. In The Interrelationship of the Body's Two Major Integrative Sistems (ed. D. T. Krieger and J. C. Hughes), pp. 177-183. Sinaver Associates: Sunderland, Mass.

Schleifer, S. J., Keller, S. E.. Meyerson, A. T., Raskin, M. J., Davis, K. L. \& Stein, M. (1984). Lymphocyte function in major depressive disorder. Archives of General Psychiatry 41, 484-486.

Schleifer, S. J., Keller, S. E., Bond, R. N., Cohen, J. \& Stein, M. (1989). Major depressive disorder and immunity: role of age, sex, severity and hospitalisation. Archives of General Psychiaty 46, 8187.

Shalit, B. (1977). Structural ambiguity and limits to coping. Journal of Human Stress 3, $32-45$.

Snaith, R. (1987). The concept of mild depression. British Journal of Psychiatry 150, 387 -393.

Spitzer, R. L., Endicott, J. \& Robins, E. (1978). Research Diagnostic Criteria: rationale and reliability. Archives of General Psychiatry 35, 773782.

Straus, S. E. (1988). The chronic mononucleosis syndrome. Journal of Infectious Diseases 157, 405-412.

Straus, S. E., Tosato, G., Armstrong, G., Lawley, T., Preble, O. T. Henle, W., Davey, R., Pearson, G., Epstein, J., Brus, I. \& Blaese, R. M. (1985). Persisting illness and fatigue in adults with evidence of Epstein-Barr virus infection. Annals of Internal Medicine 102. $7-16$

Straus, S. E., Dale, J. K., Tobi, M., Lawley, T., Preble, O., Blaese, M., Hallahan, C. \& Henle, W. (1988). Acyclovir treatment of the chronic fatigue syndrome: lack of efficacy in a placebo-controlled trial. New England Journal of Medicine 319, 1692-1698.

Swartz, M. N. (1988). The chronic fatigue syndrome one entity or many? New England Journal of Medicine 319, 1726-1728.

Taerk, G. S., Toner, B. B., Salit, I. E., Garfinkel, P. E. \& Ozersky, S. (1987). Depression in patients with neuro-myasthenia (benign myalgic encephalomyelitis). International Journat of Psychiary in Medicine 17, 49-56.

Wessely, S. (1989). Myalgic encephalomyelitis - a warning: discussion paper. Journal of the Royal Society of Medicine 82. 215-217.

Wessely, S., David, A., Butler, S. \& Chalder, T. (1989). Management of chronic (post-viral) fatigue syndrome. Journal of the Royral College of General Practitioners 39, 26-29.

Wessely, S. \& Powell, R. (1989). Fatigue syndrome: a comparison of 'postviral' fatigue with neuromuscular and affective disorder. Journal of Neurology, Neurosurgery and Psychiary' 52, 940948.

Wittenborn, J. \& Buhler, R. (1979). Somatic discomforts among depressed women. Archives of General Psychiatry 36, 465471.

Zigmund, A. S. \& Snaith, R. P. (1983). The Hospital Anxiety and Depression Scale. Acta Psychiatrica Scandinavica 67, 361370. 